\title{
NUEVO RELIEVE CERVANTINO DE ANTONIO CASTILLO LASTRUCCI
}

\author{
A NEW CERVANTINE'S RELIEF BY \\ ANTONIO CASTILLO LASTRUCCI
}

\author{
Jesús Rojas-Marcos GonZÁlez \\ Universidad de Sevilla, España \\ rojasmarcos@us.es
}

\begin{abstract}
En el presente trabajo damos a conocer una obra inédita de Antonio Castillo Lastrucci, conservada en una colección particular sevillana. Se trata de un relieve en barro cocido de temática cervantina. En particular, reproduce una escena de la célebre novela El ingenioso hidalgo don Quijote de la Mancha, una de las mejores composiciones de la literatura universal. Con ello enriquecemos el ingente y variado catálogo de tan prolífico artista, más conocido por sus famosas obras de imaginería procesional.
\end{abstract}

Palabras clave: Antonio Castillo Lastrucci; escultura; Cervantes; Don Quijote; Sevilla.

We introduce in this paper an unpublished artwork by Antonio Castillo Lastrucci, which is preserved in a private Sevillian collection. It is a terracotta relief about cervantine subject. In this case, there is represented a scene about the outstanding novel The ingenious gentleman don Quixote de la Mancha, which is considered one of the best works of universal literature. Thus an enriching contribution is made to the huge and varied catalogue of this prolific artist, who is well-known due to his famous imagery works.

Keywords: Antonio Castillo Lastrucci; sculpture; Cervantes; Don Quixote; Seville.

Miguel de Cervantes Saavedra, máximo representante de las letras españolas, falleció en Madrid el 22 de abril de 1616, a los sesenta y ocho años de edad ${ }^{1}$. En 2016 se cumplió, pues, el IV centenario de su muerte. Este aniversario, recordado en todo el mundo, tuvo una especial significación en el ámbito hispanohablante, donde se desarrollaron innumerables actividades institucionales y editoriales. Por otro lado, Antonio Castillo Lastrucci, uno de los imagineros españoles más importantes del siglo XX, murió en Sevilla el 29 de noviembre de 1967, cumplidos

${ }^{1}$ Cfr. GRACIA, Jordi: Miguel de Cervantes: la conquista de la ironía. Barcelona, 2016. 
los ochenta y nueve 2 . En 2017 se conmemoró, por tanto, el cincuentenario de su óbito. La celebración de distintos actos universitarios y académicos, particularmente en Andalucía, sirvieron para rememorar la figura de tan popular escultor hispalense.

A raíz de esta última efeméride, tuvimos la fortuna de dar con un relieve inédito de Castillo Lastrucci, conservado en una colección particular sevillana, precisamente de temática cervantina. En concreto, reproduce un pasaje de asunto quijotesco. Al respecto, sabido es que Cervantes escribió El ingenioso hidalgo don Quijote de la Mancha, editado en 1605, cuya segunda parte se publicó en 1615. La obra está considerada como la primera novela moderna y una de las mejores composiciones de la literatura universal. Desde su aparición ha sido continuamente ilustrada. Razón por la que su inmortal protagonista ha inspirado, durante más de cuatro siglos, a infinidad de creadores de toda clase y condición ${ }^{3}$.

Las figuras de Cervantes, en general, y del Quijote, en particular, están presentes en la producción de Castillo Lastrucci. Sobre todo, en su primera etapa artística, que se desarrolla hasta 1922, cuando inicia su andadura en la imaginería procesional $^{4}$. Así, en 1915, participó en el concurso para erigir un monumento a Cervantes en Madrid. Al año siguiente se cumplía el III centenario de la muerte del "Príncipe de los Ingenios". Su boceto, el n 46, contó con la participación del arquitecto Antonio Azcoalo ${ }^{5}$. El escultor conservó en su estudio el anteproyecto. Se sabe que, antes de 1930, realizó el busto Cervantes, custodiado también en su obrador; y un grupo del mismo título, antiguamente propiedad en Sevilla de José Benjumea Zayas. Todo ello se reseña en una publicación con la relación de las obras ejecutadas por el artista ${ }^{6}$.

Respecto a las creaciones inspiradas en el Quijote, hizo, al menos, un grupo en bronce y numerosos relieves en barro cocido, por influencia de su maestro Antonio Susillo (1855-1896). Consta que en 1915 presentó dos bajorrelieves de dicho

${ }^{2}$ GONZÁlEZ GÓMEZ, Juan Miguel y ROJAS-MARCOS GONZÁLEZ, Jesús: Antonio Castillo Lastrucci. T. I. Sevilla, 2009, p. 87.

${ }^{3}$ Cfr. REYERO, Carlos: "Los mitos cervantinos en pintura y escultura. Del arrebato romántico a la interiorización noventayochista", en Cervantes y el mundo cervantino en la imaginación romántica. Madrid, 1997, pp. 89-199; ALVAR, Carlos et al.: La imagen del Quijote en el mundo. Barcelona, 2004; ALLEN, John J. y FINCH, Patricia S.: Don Quijote en el arte y pensamiento de occidente. Madrid, 2004; y LUCÍA MEGÍAS, José Manuel: Los primeros ilustradores del Quijote. Madrid, 2005.

${ }^{4}$ TOBAJAS, Manuel: "XXV aniversario de la muerte de Castillo Lastrucci (II)", $A B C, 31-3-1992$, p. 64.

5 "El monumento á Cervantes. Los anteproyectos", Nuevo Mundo, no 1136, 15-101915, pp. 17-18.

${ }^{6}$ Antonio Castillo Lastrucci. Escultor artístico. Relación de las obras ejecutadas. Sevilla, 1930, pp. 13, 17 y 19. 
tema a la Exposición de Bellas Artes de Primavera; y una obra a la de 1917. Por estos años debió modelar los relieves Don Quijote en casa de los Duques, propiedad de Luis Rojas en Sevilla; y otros dieciocho con asuntos del Quijote sin especificar. Estos últimos se conservaban en colecciones sevillanas: dos, en la del citado señor Benjumea; uno, en la de Juan Talavera; dos, en la de Juan López; seis, en la de Eugenio López; cinco, en la de María García; y dos, en el estudio del propio autor ${ }^{8}$. También se ha afirmado que el general Franco poseía relieves quijotescos salidos de sus manos?

Desde el punto de vista cronológico, tales piezas coinciden con el entusiasmo suscitado con motivo de la celebración de las efemérides cervantinas de principios del siglo XX. A alguno de esos relieves, donde no se precisa el pasaje representado del Quijote, podría corresponder el que damos a conocer en este trabajo. Antes de pasar a su análisis, es necesario examinar otro ejemplar de Castillo Lastrucci, nunca antes estudiado en profundidad, con el que se relaciona directamente. Se titula Todo el mundo se tenga y, al narrar la escena previa, permite comprender en su totalidad la obra inédita que presentamos y, de paso, admirar también la capacidad discursiva de su autor, que conecta con versatilidad ambos episodios. Dicha terracota en su color natural está firmada, localizada en Sevilla y fechada en 1914, en el ángulo superior izquierdo, tal como lo ve el espectador (Figura 1). Junto a la rúbrica se incluye el título de la pieza en letras capitales. Fue publicada en 2009, encontrándose hoy en paradero desconocido ${ }^{10}$.

Reproduce una escena del capítulo IV de la primera parte de la obra. Se trata de la segunda aventura de Don Quijote, tras ser armado caballero en una venta. Estaba de regreso a su casa, cuando vio llegar a unos mercaderes toledanos que iban a comprar seda a Murcia, que él tuvo y juzgó por caballeros andantes. Puesto en la mitad del camino, esperó a que llegasen y les dijo en voz alta y con arrogante ademán: "Todo el mundo se tenga, si todo el mundo no confiesa que no hay en el mundo todo doncella más hermosa que la emperatriz de la Mancha, la simpar Dulcinea del Toboso". Según Rodríguez Marín, la insistente repetición de "todo" manifiesta el andalucismo de Cervantes. Sea como fuere, tan contundente aserto ilustra a la perfección el carácter hiperbólico de Don Quijote ${ }^{11}$.

Castillo Lastrucci recrea con exactitud la narración cervantina. Elige un formato apaisado, dividido en dos mitades. A la derecha aparece Don Quijote, solo,

7 PÉREZ CALERO, Gerardo: Las Bellas Artes y el Ateneo de Sevilla. La vida artística de la ciudad (1887-1950). I. Sevilla, 2006, pp. 214 y 244.

${ }^{8}$ Antonio Castillo Lastrucci. Escultor artístico..., op. cit., pp. 15-17.

9 DE LA ROSA MATEOS, Antonio: Castillo Lastrucci. Su obra. Almería, 2004, p. 244.

${ }^{10}$ GONZÁLEZ GÓMEZ, Juan Miguel y ROJAS-MARCOS GONZÁLEZ, Jesús: Antonio Castillo Lastrucci..., op. cit., t. I, p. 53, y t. II, p. 329.

${ }^{11}$ DE CERVANTES SAAVEDRA, Miguel: El ingenioso hidalgo don Quijote de la Mancha. T. I. Madrid, 1987, pp. 110-111. 
a lomos de Rocinante, cuyas riendas sostiene con la mano izquierda. Su aspecto se corresponde con la descripción del personaje: "Frisaba la edad de nuestro hidalgo con los cincuenta años: era de complexión recia, seco de carnes, enjuto de rostro" ${ }^{2}$. Va armado con lanza, adarga y coselete. Alzada la visera de la celada, levanta el brazo derecho para detener e interpelar a los mercaderes, que ocupan el flanco izquierdo de la composición. El escultor interpreta fielmente el texto original, al decir que eran "seis, y venían con sus quitasoles, con otros cuatro criados a caballo y tres mozos de mulas a pie"13.

El grupo de mercaderes, modelado en alto, medio y bajorrelieve, es un rico muestrario de variados gestos y actitudes. Algunos, sorprendidos, se detienen absortos; pero la mayoría, a juzgar por sus elocuentes expresiones, ha captado al instante su falta de juicio. El desenlace es bien conocido. Uno de ellos, atrevido y burlón, encolerizó a Don Quijote, que intentó arremeterlo con su lanza. Al tropezar Rocinante, cayó al suelo sin poder levantarse. En ese momento, un mozo de mulas aprovechó para partir la lanza y apalearlo con los propios pedazos, dejando molido y casi deshecho al caballero.

Dicho esto, pasamos al relieve inédito objeto de nuestro estudio, que se suma así al amplio catálogo del artista (Figura 2). A tenor de la colección particular sevillana donde se conserva, podría identificarse, quizás, con uno de los dos ejemplares quijotescos ya mencionados que eran propiedad del autor. Está modelado en barro cocido sin policromar. Mide 34 x 34 x $6 \mathrm{~cm}$. Y está firmado y localizado en el ángulo inferior izquierdo: "A. Castillo Lastrucci/ Sevilla 19". No conserva los dos últimos dígitos de la fecha. Sin embargo, podría datarse hacia 1914, año de la terracota precedente. En el ángulo superior izquierdo, el artista pintó en rojo el título de la pieza, de nuevo en letras mayúsculas: "HACIA SU PUEBLO".

En efecto, dicha leyenda está tomada de uno de los primeros párrafos del capítulo $\mathrm{V}$, que continúa la narración de la desgracia de nuestro protagonista, enlazando de este modo con el relieve estudiado con anterioridad. Cuenta que Don Quijote empezó a revolcarse y a recitar el romance del marqués de Mantua. En ese estado lo halló un labrador, Pedro Alonso, vecino suyo, que lo reconoció al instante. Entonces, "no con poco trabajo le subió sobre su jumento... Recogió las armas, hasta la astillas de la lanza, y liólas sobre Rocinante, al cual tomó de la rienda, y del cabestro al asno, y se encaminó hacia su pueblo, bien pensativo de oír los disparates que don Quijote decía"14.

Este pasaje es el reproducido, ad pedem litterae, por Castillo Lastrucci. En esta ocasión, el relieve adopta un formato cuadrangular. Las cuatro figuras, enmarcadas por una espesa vegetación, se colocan en un agreste exterior, ocupando la mitad inferior del esquema compositivo. El labrador, de espaldas, camina hacia

\footnotetext{
12 Ibidem, pp. 52-53.

13 Ibid., p. 110.

${ }^{14}$ Ibid., p. 120.
} 
la izquierda, tirando de ambos animales. Su postura encorvada aporta credibilidad a la acción y, al estar modelado en bajorrelieve, incrementa la sensación de lejanía. Tanto la actitud como el efecto de perspectiva intensifican la dosis de movimiento, necesaria en toda escena itinerante. En segundo plano, Rocinante transporta sobre la silla de montar la panoplia, descrita con auténtico lujo de detalles. Y en el centro, en altorrelieve, Don Quijote, extenuado, se desploma bocarriba a lomos del burro. El artista sevillano se atiene magistralmente a la prosa cervantina, ya que el Caballero de la Triste Figura, "de puro molido y quebrantado, no se podía tener sobre el borrico, y de cuando en cuando daba unos suspiros que los ponía en el cielo"15.

En definitiva, Castillo Lastrucci, experto barrista, narra de manera consecutiva, en uno y otro relieve, las vicisitudes de Don Quijote en su segunda aventura. En ambos dulcifica las formas, suaviza las estructuras compositivas y subraya el dinamismo de las figuras sin forzar las actitudes. La gracia y soltura de su buen hacer responden a una extraordinaria habilidad escultórica. De ahí que estas obras quijotescas prueben, una vez más, que su facilidad narrativa y desbordante imaginación inducen al espectador a involucrarse en el tema y completar la representación escenográfica. Y, en especial, la pieza inédita que presentamos, Hacia su pueblo, confirma a su autor como uno de los escultores más prolíficos de la escuela sevillana.

Fecha de recepción: 29 de octubre de 2017

Fecha de aceptación: 30 de enero de 2018

15 Ibid. 


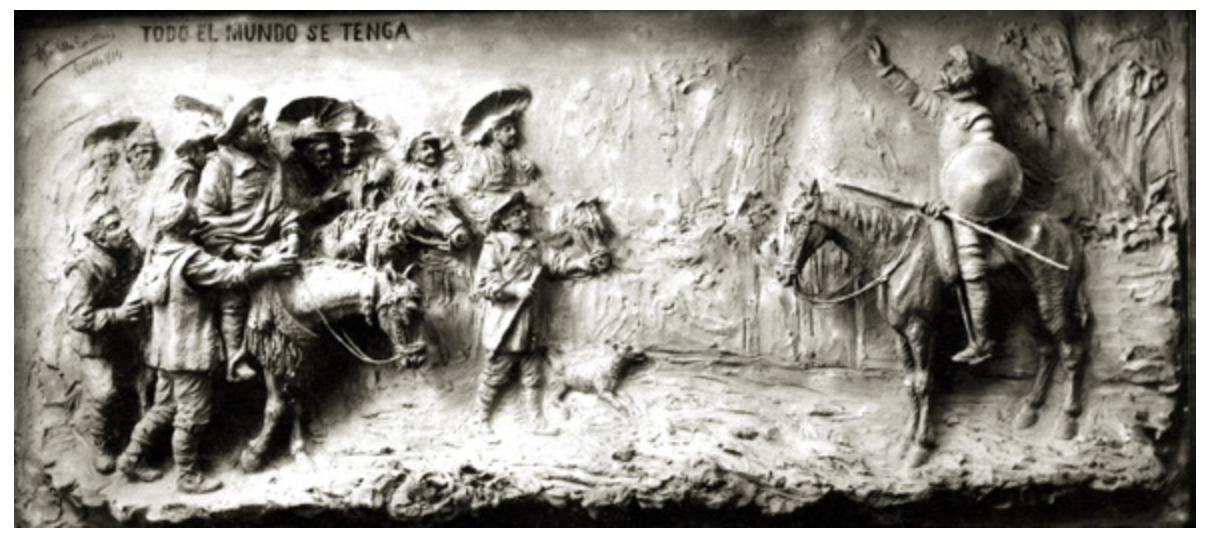

Figura 1. Antonio Castillo Lastrucci, Todo el mundo se tenga, 1914, paradero desconocido. 


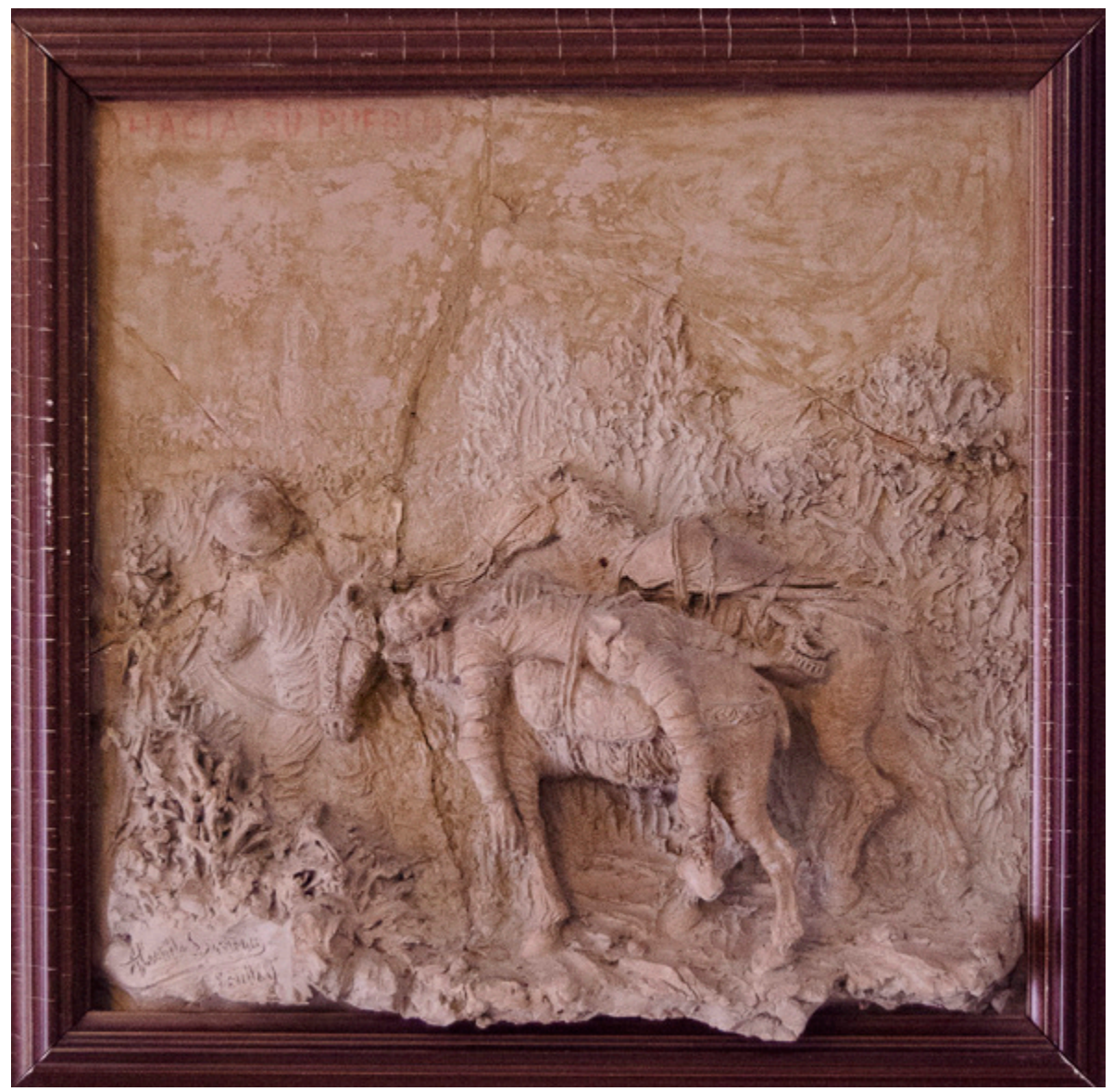

Figura 2. Antonio Castillo Lastrucci, Hacia su pueblo, hacia 1914, colección particular, Sevilla. Foto: Jesús Rojas-Marcos González. 